This is the author's final, peer-reviewed manuscript as accepted for publication. The publisher-formatted version may be available through the publisher's web site or your institution's library.

\title{
Dose dependent effects of nitrate supplementation on cardiovascular control and microvascular oxygenation dynamics in healthy rats
}

Scott K. Ferguson, Daniel M. Hirai, Steven W. Copp, Clark T. Holdsworth, Jason D. Allen, Andrew M. Jones, Timothy I. Musch, David C. Poole

\section{How to cite this manuscript}

If you make reference to this version of the manuscript, use the following information:

Ferguson, S. K., Hirai, D. M., Copp, S. W., Holdsworth, C. T., Allen, J. D., Jones, A. M., Musch, T. I., \& Poole, D. C. (2014). Dose dependent effects of nitrate supplementation on cardiovascular control and microvascular oxygenation dynamics in healthy rats. Retrieved from http://krex.ksu.edu

\section{Published Version Information}

Citation: Ferguson, S. K., Hirai, D. M., Copp, S. W., Holdsworth, C. T., Allen, J. D., Jones, A. M., Musch, T. I., \& Poole, D. C. (2014). Dose dependent effects of nitrate supplementation on cardiovascular control and microvascular oxygenation dynamics in healthy rats. Nitric Oxide, 39, 51-58.

Copyright: () 2014 Elsevier Inc.

Digital Object Identifier (DOI): doi:10.1016/j.niox.2014.04.007

Publisher's Link: http://www.sciencedirect.com/science/article/pii/S1089860314002055

This item was retrieved from the K-State Research Exchange (K-REx), the institutional repository of Kansas State University. K-REx is available at http://krex.ksu.edu 


\section{Dose dependent effects of nitrate supplementation on cardiovascular control and microvascular oxygenation dynamics in healthy rats}

Scott K. Ferguson ${ }^{1}$, Daniel M. Hirai ${ }^{1}$, Steven W. Copp ${ }^{1}$, Clark T. Holdsworth ${ }^{1}$, Jason D. Allen ${ }^{3}$, Andrew M. Jones ${ }^{4}$, Timothy I. Musch ${ }^{1,2}$, David C. Poole ${ }^{1,2}$

${ }^{1}$ Department of Anatomy and Physiology, ${ }^{2}$ Department of Kinesiology, Kansas State University, Manhattan, KS, 66506, USA

${ }^{3}$ Department of Community and Family Medicine, Department of Medicine, Duke University, Durham, NC, 27710, USA

${ }^{4}$ Sport and Health Sciences, University of Exeter, St. Luke's Campus, Exeter, EX12LU, UK

Running title: Dose dependent vascular effects of dietary nitrate supplementation in rats

Corresponding author: Scott K. Ferguson

Department of Anatomy and Physiology

College of Veterinary Medicine

Kansas State University

Manhattan, KS 66506-5802

Tel.: 785-532-4476

e-mail: skfergus@vet.ksu.edu 


\begin{abstract}
High dose nitrate $\left(\mathrm{NO}_{3}{ }^{-}\right)$supplementation via beetroot juice (BR, $1 \mathrm{mmol} / \mathrm{kg} /$ day) lowers mean arterial blood pressure (MAP) and improves skeletal muscle blood flow and $\mathrm{O}_{2}$ delivery/utilization matching thereby raising microvascular $\mathrm{O}_{2}$ pressure $\left(\mathrm{PO}_{2} m v\right)$. We tested the hypothesis that a low dose of $\mathrm{NO}_{3}{ }^{-}$supplementation, consistent with a diet containing $\mathrm{NO}_{3}{ }^{-}$rich vegetables (BRLD, $0.3 \mathrm{mmol} / \mathrm{kg} / \mathrm{day}$ ), would be sufficient to cause these effects. Male SpragueDawley rats were administered a low dose of $\mathrm{NO}_{3}{ }^{-}(0.3 \mathrm{mmol} / \mathrm{kg} / \mathrm{day} ; n=12)$, a high dose (1 $\mathrm{mmol} / \mathrm{kg} /$ day; BRHD, $\mathrm{n}=6$ ) or tap water (control, $n=10$ ) for 5 days. MAP, heart rate $(\mathrm{HR})$, blood flow (radiolabeled microspheres) and vascular conductance (VC) were measured during submaximal treadmill exercise $\left(20 \mathrm{~m} / \mathrm{min}, 5 \%\right.$ grade, equivalent to $\sim 60 \%$ of maximal $\mathrm{O}_{2}$ uptake). Subsequently, $\mathrm{PO}_{2} \mathrm{mv}$ (phosphorescence quenching) was measured at rest and during $180 \mathrm{~s}$ of electrically-induced twitch contractions ( $1 \mathrm{~Hz}, \sim 6$ volts) of the surgically-exposed spinotrapezius muscle. BRLD and BRHD lowered resting (control: 139 \pm 4 , BRLD: 124 \pm 5 , BRHD: $128 \pm 9$ $\mathrm{mmHg}, P<0.05$ ) and exercising (control: 138 \pm 3 , BRLD: $126 \pm 4$, BRHD: $125 \pm 5 \mathrm{mmHg}, P<0.05$ ) MAP to a similar extent. For BRLD this effect occurred in the absence of altered exercising hindlimb muscle(s) blood flow or spinotrapezius $\mathrm{PO}_{2} m v$ (rest and across the transient response at the onset of contractions, all $P>0.05$ ), each of which increased significantly for the BRHD condition (all $\mathrm{P}<0.05$ ). Whereas BRHD slowed the $\mathrm{PO}_{2} m v$ kinetics significantly (i.e., $>$ mean response time, MRT; control: $16.6 \pm 2.1$, BRHD: $23.3 \pm 4.7 \mathrm{~s}$ ) following the onset of contractions compared to control, in the BRLD group this effect did not reach statistical significance (BRLD: $20.9 \pm 1.9 \mathrm{~s}, P=0.14)$. These data demonstrate that while low dose $\mathrm{NO}_{3}{ }^{-}$supplementation lowers MAP it does so in the absence of augmented muscle blood flow, $\mathrm{VC}$ and $\mathrm{PO}_{2} m v$; all of which are elevated at a higher dose. Thus, in healthy animals, a high dose of $\mathrm{NO}_{3}{ }^{-}$supplementation seems necessary to elicit significant changes in exercising skeletal muscle $\mathrm{O}_{2}$ delivery/utilization.
\end{abstract}

\footnotetext{
Key words: nitric oxide; exercise; dietary nitrate; nitrite; mean arterial pressure; blood flow
} 


\section{Introduction}

A fundamental tenet of exercise physiology is that blood flow (BF) increases following exercise onset to meet the rising skeletal muscle energetic demands. This hyperemic response is mediated by a host of vasodilatory controllers (Joyner and Wilkins, 2007) and it is now widely accepted that nitric oxide (NO) plays a deterministic role in regulating not only $\mathrm{O}_{2}$ delivery $\left(\mathrm{QO}_{2}\right)$ (Hirai et al. 1994; reviewed by Joyner and Tschakovsky, 2004), but also $\mathrm{O}_{2}$ utilization ( $\dot{V} \mathrm{O}_{2}$ ) within the skeletal muscle (Andrade et al. 1998; Larsen et al 2012). A growing body of evidence suggests that ingestion of inorganic nitrate $\left(\mathrm{NO}_{3}{ }^{-}\right)$, for example via beetroot juice (BR), can, following a step-wise reduction, elevate NO bioavailability and thus impact skeletal muscle hemodynamic and metabolic function during exercise (Larsen et al. 2007; Bailey et al. 2009; Vanhatalo et al. 2010; Kenjale et al. 2011; Lansley et al. 2011a,b; Ferguson et al. 2013a,b).

In humans, $\mathrm{NO}_{3}{ }^{-}$supplementation via $\mathrm{BR}$ reduces blood pressure and enhances exercise tolerance in both healthy (Bailey et al. 2009; Vanhatalo et al. 2010; Lansley et al. 2011a,b; Cermak et al. 2012; Wylie et al. 2013b) and patient populations (i.e., peripheral arterial disease, Kenjale et al. 2011). These effects appear to have a dose-dependent response with no additional improvement in exercise tolerance after ingesting BR containing 16.8 compared to $8.4 \mathrm{mmol}$ $\mathrm{NO}_{3}{ }^{-}$(Wylie et al. 2013a). The precise mechanisms for these improvements are not yet fully understood. However, recent investigations using murine models implicate enhanced exercising muscle BF (i.e., $\uparrow \mathrm{QO}_{2}$, Ferguson et al. 2013a) and $\mathrm{QO}_{2} / \dot{V} \mathrm{O}_{2}$ matching (e.g. microvascular $\mathrm{PO}_{2}$; $\mathrm{PO}_{2} m v$, Ferguson et al. 2013b) combined with greater contractile efficiency (e.g. $\downarrow \dot{\mathrm{V}} \mathrm{O}_{2}$; Hernandez et al. 2012). 
Many disease states impair exercise tolerance and its restoration is a primary therapeutic goal. What is not known is whether lower doses of $\mathrm{NO}_{3}{ }^{-}$alter cardiovascular control and muscle oxygenation (i.e. $\mathrm{PmvO}_{2}$, which sets the pressure head for capillary-myocyte $\mathrm{O}_{2}$ flux) during exercise. Specifically, one question of paramount ecological importance is whether $\mathrm{NO}_{3}{ }^{-}$dosing consistent with an individual eating a diet rich in leafy greens and other $\mathrm{NO}_{3}{ }^{-}$sources can achieve the cardiovascular and muscular benefits without the necessity for supplementation per se. Thus, we tested the hypotheses that a low dose of $\mathrm{NO}_{3}{ }^{-}$supplementation (i.e. consistent with a diet containing $\mathrm{NO}_{3}{ }^{-}$rich vegetables, $0.3 \mathrm{mmol} / \mathrm{kg} /$ day) would be sufficient to 1) raise plasma $\left[\mathrm{NO}_{3}{ }^{-}\right]$and $\left.\left[\mathrm{NO}_{2}^{-}\right], 2\right)$ lower mean arterial pressure (MAP) at rest and during exercise, 3 ) elevate $\mathrm{BF}$ and vascular conductance (VC) in locomotory muscles of the hindlimb and 4) raise the $\mathrm{PO}_{2} m v$ of the mixed fiber-type spinotrapezius muscle during the crucial rest-contractions transient. 


\section{Methods}

\section{Animal selection and care}

Thirty-one young adult male Sprague-Dawley rats ( 3-4 months of age, Charles River Laboratories, Wilmington, MA,USA) were used in this investigation. Rats were maintained in accredited animal facilities at Kansas State University on a 12/12 hr light-dark cycle with food and water provided ad libitum. All procedures were approved by the Institutional Animal Care and Use Committee of Kansas State University and conducted according to National Institutes of Health guidelines. All rats were familiarized with running on a custom-built motor-driven treadmill for $5 \mathrm{~min} /$ day at a speed of $20 \mathrm{~m} / \mathrm{min}$ up a $5 \%$ grade for $\sim 5$ days.

\section{Supplementation protocol}

Rats were randomly assigned to receive 5 days of BR supplementation with either a low $\mathrm{NO}_{3}{ }^{-}$dose of $0.3 \mathrm{mmol} / \mathrm{kg} /$ day $(\mathrm{BRLD} ; \mathrm{n}=14)$, a higher $\mathrm{NO}_{3}{ }^{-}$dose of $1 \mathrm{mmol} / \mathrm{kg} /$ day $(\mathrm{BRHD}$; $\mathrm{n}=6$, Beet it ${ }^{\mathrm{TM}}$, James White Drinks, Ipswich UK) or untreated tap water (control; $\mathrm{n}=11$ ) with consumption monitored. For both BRLD and BRHD rats, two days' worth of BR was diluted in $100 \mathrm{ml}$ of tap water (average daily fluid consumption $\sim 50-60 \mathrm{ml} /$ day). This lower $\mathrm{NO}_{3}{ }^{-}$dose $(0.3$ $\mathrm{mmol} / \mathrm{kg} /$ day) represents a dose found in a diet containing $\mathrm{NO}_{3}{ }^{-}$rich vegetables, while the higher $\mathrm{NO}_{3}{ }^{-}$dose $(1 \mathrm{mmol} / \mathrm{kg} /$ day $)$ represents a dietary supplement with a $\mathrm{NO}_{3}{ }^{-}$concentration similar to that used by Jones and colleagues (Bailey et al. 2009; Vanhatalo et al. 2010; Lansley et al. $2011 \mathrm{a}, \mathrm{b})$ after accounting for the resting metabolic rate of rats $(\sim 7 \mathrm{x}$ that of humans, Henson et al. 1987; Musch et al. 1988). In an effort to minimize the unnecessary utilization of additional animals, both control and BRHD data presented herein represent a randomly selected subset of animals published recently. The BRHD data represent a $\mathrm{NO}_{3}{ }^{-}$dose of $1 \mathrm{mmol} / \mathrm{kg} / \mathrm{day}$ and 
demonstrate a significant vascular effect of supplementation (Ferguson et al. 2013ab). Data from the BRLD group were obtained within the same time-frame as control and BRHD groups presented in Ferguson et al. (2013ab, e.g. within 16 weeks). In this way any potential seasonal differences or variations in rat-chow content were avoided.

\section{Surgical instrumentation}

Rats were anaesthetized with a $5 \%$ isoflurane- $\mathrm{O}_{2}$ mixture and maintained subsequently on $3 \%$ isoflurane- $\mathrm{O}_{2}$. The carotid artery was isolated and cannulated with a catheter (PE-10 connected to PE-50, Intra-Medic polyethylene tubing, Clay Adams Brand, Becton, Dickinson and Company, Sparks, MD) for the measurement of MAP and HR, infusion of the phosphorescent probe (see below), and arterial blood sampling. A second catheter was placed in the caudal artery. The incisions were then closed and rats were given $>1 \mathrm{hr}$ to recover (Flaim et al. 1984).

\section{Protocol 1: Measurement of hindlimb skeletal muscle blood flow}

After recovery, rats were placed on the treadmill and the caudal artery catheter was connected to a $1 \mathrm{ml}$ syringe chambered in a Harvard infusion/withdrawal pump (model 907, Cambridge, MA, USA). The carotid artery catheter was connected to a pressure transducer (Gould Statham P23ID, Valley View, OH, USA) maintained at the same height as the animal. Exercise was initiated and treadmill speed was increased progressively over a $\sim 30 \mathrm{~s}$ period to a speed of $20 \mathrm{~m} / \mathrm{min}$ ( $5 \%$ grade, $\sim 60 \% \dot{\mathrm{V}} \mathrm{O}_{2} \mathrm{O}_{2}$ max; Musch et al. 1988). The rat continued to exercise for another 2.5 min until a total time of 3 min was reached. At 3 min the Harvard pump was activated and withdrawal was initiated at a rate of $0.25 \mathrm{ml} \cdot \mathrm{min}^{-1}$. Simultaneously, HR and MAP were measured and recorded using the carotid artery catheter. The carotid artery catheter 
was then disconnected from the pressure transducer and 0.5-0.6 $\times 10^{6} 15 \mu \mathrm{m}$ diameter radiolabeled microspheres $\left({ }^{57} \mathrm{Co}\right.$ or ${ }^{85} \mathrm{Sr}$ in random order; Perkin Elmer, Waltham, MA, USA) were infused into the aortic arch for determination of regional BF. Following the microsphere infusion $\sim 0.2 \mathrm{ml}$ of blood was sampled from the carotid artery catheter for the determination of blood lactate concentration ([lactate]) (Nova Stat Profile M, Nova Biomedical, Waltham, MA, USA) after which exercise was terminated.

Following a minimum $1 \mathrm{hr}$ recovery period, a second microsphere infusion (differently radio-labeled than the first) was performed while the rat sat quietly on the treadmill for the determination of resting BF, HR and MAP. This experimental strategy (i.e. exercise before rest) mitigates potential influences of the pre-exercise anticipatory response on resting skeletal muscle BF measurements (Armstrong et al. 1989).

\section{Protocol 2: Measurement of spinotrapezius muscle $\mathrm{PO}_{2} \mathrm{mv}$}

Following the second (resting) microsphere infusion, rats were anesthetized progressively using diluted pentobarbital sodium anesthesia (administered into the caudal artery catheter to effect) with the level of anesthesia monitored continuously via the toe-pinch and blink reflexes. Rats were then placed on a heating pad to maintain core temperature at $\sim 38{ }^{\circ} \mathrm{C}$ (measured via rectal probe). Overlying skin and fascia were reflected carefully from the mid-dorsal caudal region of each rat and the right spinotrapezius muscle was carefully exposed in a manner that ensured the integrity of the neural and vascular supply to the muscle (Bailey et al. 2000). Silver wire electrodes were sutured (6-0 silk) to the rostral (cathode) and caudal (anode) regions of the muscle. The exposed spinotrapezius muscle was continuously superfused with a warmed $\left(38^{\circ} \mathrm{C}\right)$ Krebs-Henseleit bicarbonate buffered solution equilibrated with $5 \% \mathrm{CO}_{2}-95 \% \mathrm{~N}_{2}$ and surrounding exposed tissue was covered with Saran wrap (Dow Brands, Indianapolis, IN). The 
spinotrapezius muscle was selected specifically based on its mixed muscle fiber-type composition and citrate synthase activity close to that found in human quadriceps muscle (Delp \& Duan 1996; Leek et al. 2001).

The phosphorescent probe palladium meso-tetra (4 carboxyphenyl)porphyrin dendrimer (R2: $15-20 \mathrm{mg} \cdot \mathrm{kg}^{-1}$ dissolved in $0.4 \mathrm{ml}$ saline) was infused via the carotid artery catheter. After a brief stabilization period ( $\sim 10 \mathrm{~min})$, the common end of the light guide of a frequency domain phosphorometer (PMOD 5000, Oxygen Enterprises, Philadelphia, PA) was positioned $\sim 2-4 \mathrm{~mm}$ superficial to the dorsal surface of the exposed right spinotrapezius muscle over a randomly selected muscle field absent of large vessels thus ensuring that the region contained principally capillary blood. $\mathrm{PO}_{2} m v$ was measured via phosphorescence quenching (see below) and reported at $2 \mathrm{~s}$ intervals throughout the duration of the $180 \mathrm{~s}$ contraction protocol $(1 \mathrm{~Hz}, \sim 6 \mathrm{~V}, 2 \mathrm{~ms}$ pulse duration) elicited via a Grass stimulator (model S88, Quincy, MA). Following the contraction period it was ensured that $\mathrm{P} v \mathrm{O}_{2}$ returned to baseline values (indicative of preserved vasomotor

function). Rats were euthanized via pentobarbital sodium overdose $(\geq 50 \mathrm{mg} / \mathrm{kg}$ administered into the carotid artery catheter).

\section{$\mathrm{PO}_{2} \mathrm{mv}$ measurement and curve-fitting}

The Stern-Volmer relationship allows the calculation of $\mathrm{PO}_{2} \mathrm{mv}$ through the direct measurement of a phosphorescence lifetime via the following equation (Rumsey et al., 1988):

$\mathrm{PO}_{2 m v}=\left[\left(\tau^{\circ} / \tau\right)-1\right] /\left(\mathrm{k}_{\mathrm{Q}} \times \tau^{\circ}\right)$ 
where $\mathrm{k}_{\mathrm{Q}}$ is the quenching constant and $\tau^{\circ}$ and $\tau$ are the phosphorescence lifetimes in the absence of $\mathrm{O}_{2}$ and the ambient $\mathrm{O}_{2}$ concentration, respectively. For $\mathrm{R} 2, \mathrm{k}_{\mathrm{Q}}$ is $409 \mathrm{mmHg} \mathrm{g}^{-1} \cdot \mathrm{s}^{-1}$ and $\tau^{\circ}$ is $601 \mu$ s (Lo et al., 1997) and these characteristics do not change over the physiological range of $\mathrm{pH}$ and temperature in the rat in vivo and, therefore, the phosphorescence lifetime is determined directly by the $\mathrm{O}_{2}$ pressure (Rumsey et al., 1988; Lo et al., 1997).

The R2 phosphorescent probe binds to albumin, and consequently, is uniformly distributed throughout the plasma. A previous study from our laboratory investigated systematically the compartmentalization of $\mathrm{R} 2$ and confirmed that it remains within the microvasculature of exposed muscle over the duration considered in the present experiments, thereby ensuring a valid $\mathrm{PO}_{2} m v$ measurement (Poole et al., 2004).

Curve-fitting of the measured $\mathrm{PO}_{2} m v$ responses was performed with commercially available software (SigmaPlot 11.01, Systat Software, San Jose, CA) and the data were fit with either a one- or two-component model as described below:

One component: $\mathrm{PO}_{2} m v_{(\mathrm{t})}=\mathrm{PO}_{2} m v_{(\mathrm{BL})}-\Delta \mathrm{PO}_{2} m v\left(1-\mathrm{e}^{-(\mathrm{t}-\mathrm{TD}) / \tau}\right)$

Two component: $\mathrm{PO}_{2} m v_{(\mathrm{t})}=\mathrm{PO}_{2} m v_{(\mathrm{BL})}-\Delta_{1} \mathrm{PO}_{2} m v\left(1-\mathrm{e}^{-\left(\mathrm{t}-\mathrm{TD}_{1}\right) / \tau_{1}}\right)+\Delta_{2} \mathrm{PO}_{2} m v\left(1-\mathrm{e}^{-\left(\mathrm{t}-\mathrm{TD}_{2}\right) / \tau_{2}}\right)$

where $\mathrm{PO}_{2} m v_{(\mathrm{t})}$ represents the $\mathrm{PO}_{2} m v$ at any given time t, $\mathrm{PO}_{2} m v_{(\mathrm{BL})}$ corresponds to the precontracting resting baseline $\mathrm{PO}_{2} m v, \Delta_{1}$ and $\Delta_{2}$ are the amplitudes for the first and second components, respectively, $\mathrm{TD}_{1}$ and $\mathrm{TD}_{2}$ are the time delays for each component, and $\tau_{1}$ and $\tau_{2}$ are the time constants (i.e., time to $63 \%$ of the final response value) for each component. Goodness of fit was determined using the following criteria: 1) the coefficient of determination, 2) sum of the squared residuals, and 3) visual inspection and analysis of the model fits to the data and the 
residuals. The mean response time (MRT) of the kinetics response was calculated for the first component in order to provide an index of the overall principal kinetics response according to the following equation:

$\mathrm{MRT}_{1}=\mathrm{TD}_{1}+\tau_{1}$

where $\mathrm{TD}_{1}$ and $\tau_{1}$ are as described above. The delta of the initial $\mathrm{PO}_{2} m v$ fall following contractions onset was normalized to $\tau_{1}\left(\Delta_{1} \mathrm{PO}_{2} m v / \tau_{1}\right)$ to provide an index of the relative rate of fall. Additionally, the time taken to reach $63 \%$ of the initial $\mathrm{PO}_{2} m v$ fall was determined independently from the modeling procedures $\left(\mathrm{T}_{63}\right)$ to ensure appropriateness of the model fits. Specifically, the raw $\mathrm{PO}_{2} m v$ data were interpolated, and the time coinciding with $63 \%$ of the total amplitude $\left(\Delta\right.$ total $\left.\mathrm{PO}_{2} m v\right)$ was determined.

\section{Determination of BF and VC}

Following euthanasia, the thorax of each rat was opened and placement of the carotid artery catheter was confirmed before the internal organs and individual muscles and muscle parts of the hindlimb were identified and excised. Upon removal, tissues were weighed and placed promptly into counting vials. Radioactivity of each tissue was determined with a gamma scintillation counter (Packard Auto Gamma Spectrometer, model 5230, Downers Grove, IL, USA). Tissue BF was then calculated using the reference sample method (Musch \& Terrell, 1992) and expressed as $\mathrm{ml} / \mathrm{min} / 100 \mathrm{~g}$. Adequate mixing of the microspheres was verified for each microsphere infusion as demonstrated by a $<15 \%$ difference in $\mathrm{BF}$ to the right and left 
kidneys and to the right and left hindlimb musculature. $\mathrm{VC}$ was calculated by normalizing $\mathrm{BF}$ to MAP and expressed as $\mathrm{ml} / \mathrm{min} / 100 \mathrm{~g} \cdot \mathrm{mmHg}^{-1}$.

\section{Blood sampling and measurement of plasma $\left[\mathrm{NO}_{3}{ }_{3}^{-}\right]$and $\left[\mathrm{NO}_{2}{ }^{-}\right]$}

Post-supplementation blood samples were collected following surgical instrumentation via the caudal artery catheter to assess 1) plasma $\left[\mathrm{NO}_{3}^{-}\right]$and $\left[\mathrm{NO}_{2}^{-}\right]$and 2) $\mathrm{pH}, \mathrm{PO}_{2}$, and $\% \mathrm{O}_{2}$ saturation. For plasma $\left[\mathrm{NO}_{3}{ }^{-}\right]$and $\left[\mathrm{NO}_{2}{ }^{-}\right], \sim 0.8 \mathrm{ml}$ of blood was drawn into heparinized tubes and rapidly centrifuged at $6000 \mathrm{~g}$ at $4^{\circ} \mathrm{C}$ for 6 minutes. Plasma was then extracted and frozen immediately at $-80^{\circ} \mathrm{C}$ for later analysis. A second $\sim 0.3 \mathrm{ml}$ blood sample was drawn and analyzed for $\mathrm{pH}, \mathrm{PO}_{2}$, and $\% \mathrm{O}_{2}$ saturation (Nova Stat Profile M, Nova Biomedical, Waltham, MA, USA).

All measurements of plasma $\mathrm{NO}_{3}{ }^{-}$and $\mathrm{NO}_{2}{ }^{-}$were performed within 30 minutes of thawing via chemiluminescence with an Ionic/Sievers NO analyzer (NOA 280i, Sievers Instruments, Boulder, $\mathrm{CO}, \mathrm{USA})$. In order to obtain plasma $\mathrm{NO}_{2}^{-}$levels and to avoid potential reduction of $\mathrm{NO}_{3}^{-}$, potassium iodide in acetic acid was used as a reductant. This reductant possesses the ability to reduce $\mathrm{NO}_{2}{ }^{-}$to $\mathrm{NO}$ but is incapable of reducing higher oxides of nitrogen (i.e. $\mathrm{NO}_{3}{ }^{-}$) thus increasing the specificity for $\mathrm{NO}_{2}{ }^{-}$. Plasma $\mathrm{NO}_{3}{ }^{-}$concentrations were then obtained using the same apparatus with the stronger reductant vanadium chloride in hydrochloric acid at a temperature of $95^{\circ} \mathrm{C}$. This stronger reductant reduces the sum of all nitrogen oxides with an oxidation state of +2 or higher (predominantly $\mathrm{NO}_{3}{ }^{-}[\mu \mathrm{M}]$ ) but also includes $\mathrm{NO}_{2}{ }^{-}$and nitrosothiols [nM]. Consequently, the signals obtained using potassium iodide were subtracted from those with vanadium chloride to provide a clearer representation of the $\mathrm{NO}_{3}{ }^{-}$ concentrations. 


\section{Statistical analysis}

Data are presented as mean \pm standard error of the mean (SEM). Results were compared within (rest vs. exercise) and between (control vs. BRLD vs. BRHD) using mixed 2-way analysis of variance (ANOVA) with Student-Newman-Keuls post hoc tests where appropriate.

Significance was accepted at $P<0.05$. 


\section{Results}

There were no between-group differences in the total hind-limb muscle/body mass ratio (control: $4.4 \pm 0.1$, BRLD: $4.3 \pm 0.1$, BRHD: $4.2 \pm 0.2 \%, P>0.05$ ). BRHD, but not BRLD, rats had significantly higher plasma $\left[\mathrm{NO}_{3}{ }^{-}\right]$and $\left[\mathrm{NO}_{2}^{-}\right]$when compared to control (Figure 1).

\section{Protocol 1: BF and VC at rest and during exercise}

MAP and HR. MAP at rest was reduced in BRLD rats compared to control. However, despite $>10 \mathrm{mmHg}$ lower average, resting MAP was not significantly different in BRHD rats when compared to control $(P=0.20$, Figure 2$)$. During treadmill exercise MAP was reduced for both BRLD and BRHD groups when compared to control (Figure 2). Neither HR at rest (control: $408 \pm 8$, BRLD: $408 \pm 17$, BRHD: $407 \pm 18$ beats/min, $P>0.05$ ) or during exercise (control: $528 \pm 10$, BRLD: $508 \pm 14$, BRHD: $525 \pm 7$ beats/min, $P>0.05$ ) was altered for BRLD or BRHD.

Blood gases, blood [lactate], hematocrit. There were no between-group differences in arterial $\mathrm{PO}_{2}, \mathrm{PCO}_{2}$, or hematocrit at rest or during exercise (data not shown, $P>0.05$ for all). Resting and exercising arterial blood [lactate] were not different among groups (Table 1, $P>0.05$ for all) but tended ( $P=0.12)$ to be lower for BRHD during exercise.

$B F$ and VC. There were no differences in resting total hindlimb skeletal muscle BF (control: $16 \pm 2$, BRLD: $19 \pm 2$, BRHD: $21 \pm 5 \mathrm{ml} / \mathrm{min} / 100 \mathrm{~g}, P>0.05$ ) or VC (control: $0.12 \pm$ 0.01, BRLD: $0.15 \pm 0.02$, BRHD: $0.16 \pm 0.03 \mathrm{ml} / \mathrm{min} / 100 \mathrm{~g} / \mathrm{mmHg}, P>0.05$ ) between groups. 
Similarly, there were no differences in resting BF or VC in any of the 28 individual hindlimb muscles or muscle parts (Table 1).

Total exercising hindlimb muscle $\mathrm{BF}$ and $\mathrm{VC}$ were greater in BRHD rats when compared to BRLD and control rats (Figure 3). Specifically, BRHD supplemented rats had greater BF in 15 , and VC in 20, of the 28 individual hindlimb muscles and muscle parts (Table 2) when compared to control and BRLD rats. There were no between-group differences in BF or VC at rest or during exercise to organs of the splanchnic region (Table 3).

\section{Protocol 2: $\mathrm{PO}_{2} \mathrm{mv}$ parameters}

Representative raw $\mathrm{PO}_{2} m v$ profiles of control, $\mathrm{BRLD}$ and $\mathrm{BRHD}$ rats are presented in Figure 4. The responses were fit by a one-component model in 2 of 11 control, 6 of 12 BRLD and 2 of 5 BRHD rats while the more complex two-component model was utilized for the remainder. The $\mathrm{r}^{2}$ (control: $0.99 \pm 0.01$, BRLD: $0.98 \pm 0.01$, BRHD: $0.98 \pm 0.01$ ) and low sum of squared residuals (control: $20.2 \pm 3.1$, BRLD: $18.3 \pm 2.7$, BRHD: $21.1 \pm 7 \mathrm{mmHg}$ ) for both groups supported that the model fits were suitable. Table 4 presents the average $\mathrm{PO}_{2} m v$ baselines and kinetics parameters. There were no differences in the $\mathrm{PO}_{2} m v_{(\mathrm{BL})}$ between groups. However, following the onset of contractions BRHD, but not BRLD, demonstrated a longer $\mathrm{TD}_{1}$, smaller first-component amplitude and slower $\mathrm{PO}_{2} m v$ kinetics (i.e., longer $\mathrm{MRT}_{1}$ ). Overall (i.e., $\mathrm{PO}_{2} m v$ (BL) minus $\mathrm{PO}_{2} m v$ (steady-state), $\left.\Delta_{\text {total }} \mathrm{PO}_{2} m v\right)$ amplitudes tended to be less in $\mathrm{BRHD}(P=0.06)$ but failed to reach statistical significance. There were no differences in $\mathrm{PO}_{2} \mathrm{mv} v_{\text {(steady-state) }}$ during contractions between groups. 


\section{Discussion}

The principal original finding of this investigation is that low dose $\mathrm{NO}_{3}{ }^{-}$supplementation via beetroot juice $(0.3 \mathrm{mmol} / \mathrm{kg} / \mathrm{day}, \mathrm{BRLD})$, at levels consistent with a diet rich in leafy green vegetables consumed by humans, lowers resting and exercising MAP. Moreover, this occurred in the absence of increased exercising skeletal muscle BF and VC which are both elevated after higher supplementation doses ( $1 \mathrm{mmol} / \mathrm{kg} /$ day, BRHD). That BRLD impacts cardiovascular control at levels that do not detectably increase circulating $\mathrm{NO}_{3}{ }^{-}$or $\mathrm{NO}_{2}{ }^{-}$suggests that central mechanisms of cardiovascular control, possibly within the rostral ventrolateral medulla (RVLM) region of the brain, are extremely sensitive to altered dietary $\mathrm{NO}_{3}{ }^{-}$intake. Given that, in humans, reductions in systolic blood pressure of $\sim 10 \mathrm{mmHg}$ (as seen with BRLD herein) have been estimated to decrease the risk of stroke by $\sim 35 \%$ and ischemic heart disease by $\sim 25 \%$ (MacMahon et al. 1990; Lewington et al. 2002; Law et al. 2003; Lawes et al. 2003; Larsen et al. 2007,2010), these findings have strong potential clinical significance. It is also pertinent that employing low dose inorganic $\mathrm{NO}_{3}{ }^{-}$supplementation may avoid or reduce the opportunity for development of $\mathrm{NO}_{3}{ }^{-}$tolerance and endothelial dysfunction (Vanhatalo et al. 2010; Omar et al. 2012) which occur especially after chronic administration of organic $\mathrm{NO}_{3}{ }^{-}$(see Wylie et al. 2013a for discussion).

\section{Relationship to existing literature}

The randomly selected subset of data from results initially reported from our laboratory (Ferguson et al. 2013a) demonstrate clearly the effects of BRHD as regards elevated skeletal muscle(s) BF and VC and reduced MAP during treadmill running. Also, as demonstrated in Figure 4, $\mathrm{PO}_{2} m v$ kinetics were slowed significantly and $\mathrm{PO}_{2} m v$ decreased less during contractions of the spinotrapezius muscle, effectively raising the microvascular $\mathrm{O}_{2}$ driving 
pressure especially across the transition period when mitochondrial $\mathrm{O}_{2}$ uptake would be rising most rapidly (Ferguson et al. 2013b). These effects can be explained by the greater $\mathrm{O}_{2}$ delivery combined with a reduced mitochondrial $\mathrm{O}_{2}$ utilization at a given workload as demonstrated in intact humans (Larsen et al. 2007; Bailey et al. 2009; Larsen et al. 2010; Wylie et al. 2013a) as well as in isolated mitochondria (Larsen et al. 2012). With respect to the BRLD and based upon the dose-response relationship reported by Wylie et al. (2013a), where a graded fall in MAP was observed from 4.2 to $8.4 \mathrm{mmol} \mathrm{NO}_{3}{ }^{-}$(supplemented via BR with no additional decrease at 16.8 mmol), we were surprised that, in rats, MAP fell to the same extent (i.e., $\sim 10 \mathrm{mmHg}$ ) with both doses. Paramount to setting the $\mathrm{NO}_{3}{ }^{-}$supplement doses herein was the consideration of the faster metabolic rate found in the resting rat $(\sim 27 \mathrm{ml} / \mathrm{kg} / \mathrm{min}$, Musch et al. 1988) when compared to humans $(3.5 \mathrm{ml} / \mathrm{kg} / \mathrm{min}$, i.e. $\sim 7-8$ fold higher per unit mass, Henson et al. 1987). Taking this into account, the doses employed (i.e., BRLD, 0.3; BRHD, $1 \mathrm{mmol} / \mathrm{kg} /$ day) correspond broadly to 3.2 and $7.4 \mathrm{mmol} /$ day, respectively in humans. Thus, with respect to species differences, the $\mathrm{NO}_{3}{ }^{-}$ derived hypotensive response becomes saturated at lower doses in rats than in their human counterparts. This effect is very different from the skeletal muscle vascular response and that of $\mathrm{PO}_{2} m v$ which are manifested only at the higher dose.

\section{Mechanisms for reduction of mean arterial pressure}

The increased VC observed in the skeletal muscle(s) of BRHD rats explain, at least in part, the reduction in MAP found at the higher dose. However, in marked contrast, skeletal muscle $\mathrm{VC}$ and $\mathrm{BF}$ were unchanged for BRLD (which was not unexpected given that circulating $\mathrm{NO}_{3}{ }^{-} / \mathrm{NO}_{2}{ }^{-}$levels were not different from control values) and thus, the reduced MAP for these animals must have a different explanation. There is evidence that NO bioavailability (from both endothelial and neuronal nitric oxide synthase, eNOS and nNOS) in higher cardiovascular neural 
control centers, for example the RVLM, impacts sympathetic outflow and controls, or at least influences, MAP regulation and can lead to a reduction and/or redistribution of cardiac output (e.g. Mayorov, 2005; Gao et al. 2008). Although not measured in this investigation, it is possible that BRLD may have altered NO bioavailability in the RVLM. Indeed, elevated NO bioavailability via overexpression of eNOS in the RVLM induces significant hypotension by elevating gamma-aminobutyric acid (GABA) production (Kishi et al. 2001). Thus, one putative mechanism for the hypotensive response invoked by BRLD relates to increased NO bioavailability in the RVLM from non-nNOS/eNOS dependent sources which may ultimately reduce sympathetic outflow. A greater $\mathrm{NO}_{3}{ }^{-}$dose may intensify this effect which could be responsible, at least in part, for the elevated renal BF and VC seen in BRHD rats herein. Furthermore, the presence of antioxidants in the BR supplement may contribute to this effect (Gao et al. 2007) and thus play a synergistic role with $\mathrm{NO}_{3}{ }^{-}$. This novel aspect of $\mathrm{BR}$ and $\mathrm{NO}_{3}{ }^{-}$ mediated cardiovascular control carries clinical implications for those suffering from renal vascular diseases (Lundberg et al. 2008; Carlstöm et al. 2011) and warrants future investigation.

Alternative mechanisms of BR induced reductions in MAP include impacts on other vascular beds, apart from the skeletal muscle vasculature. For example, BRHD rats demonstrated $26 \%$ greater renal $\mathrm{BF}$ at rest (Table 3) suggesting that the renal circulation may be prone to $\mathrm{NO}_{2}{ }^{-}$ induced vascular effects. Given that resting renal BF was not significantly elevated in BRLD rats, this particular effect may require greater local concentrations of $\mathrm{NO}_{2}{ }^{-}$to elicit significant vascular effects within the renal circulation. While not statistically significant, a mild impact of the renal circulation on the resting MAP of BRLD rats is certainly plausible and should be investigated further. What's more, the lower $\mathrm{PO}_{2}$ environment of the venous circulation may enhance the reduction of circulating $\mathrm{NO}_{2}{ }^{-}$to $\mathrm{NO}$ and other reactive nitrogen species, which 
would likely cause venodilation and a reduction in MAP. This effect would likely be exacerbated during exercise due to the robust reductions in venous blood $\mathrm{PO}_{2}$ (to values $<30 \mathrm{mmHg}$, Gonzalez et al. 1994) offering a partial explanation for the lower exercising MAP values presented in figure 2 .

\section{Experimental considerations}

The rat is a widely used and valuable experimental model to study cardiovascular and muscle metabolic control particularly during exercise. Moreover, dietary, pharmaceutical and exercise conditions can be well controlled and standardized within this population. However, determination of "equivalent" $\mathrm{NO}_{3}{ }^{-}$doses is challenging and basing such on resting metabolic rate differences found between rats and humans is only a first approximation. Importantly, in the BRHD group plasma $\left[\mathrm{NO}_{3}^{-}\right]$and $\left[\mathrm{NO}_{2}^{-}\right]$were raised to levels approximating those seen in humans following consumption of a dietary supplement high in $\mathrm{NO}_{3}^{-}$(Lundberg \& Govoni, 2004; Kenjale et al. 2011) providing additional confidence in the doses used herein. What is particularly exciting with respect to the present results is that BRLD represented a dose that evinced clear cardiovascular responses in the absence of a significant increase in plasma $\mathrm{NO}_{3}{ }^{-}$or $\mathrm{NO}_{2}{ }^{-}$and the vascular and metabolic consequences of such. This observation unveils a novel, potentially exciting, and heretofore unappreciated consequence of BR-derived $\mathrm{NO}_{3}{ }^{-}$ supplementation.

\section{Conclusions}

This investigation was the first to examine the effects of a low $(0.3 \mathrm{mmol} / \mathrm{kg} / \mathrm{day})$ and high $(1 \mathrm{mmol} / \mathrm{kg} / \mathrm{day})$ dose of $\mathrm{NO}_{3}{ }^{-}$supplementation on vascular responses at rest and during submaximal locomotory exercise in the rat. Despite the absence of elevations of plasma $\left[\mathrm{NO}_{3}^{-}\right]$ 
or $\left[\mathrm{NO}_{2}{ }^{-}\right], \mathrm{BRLD}$ evoked reductions in MAP at rest and during exercise. These cardiovascular improvements were further amplified in BRHD rats which demonstrated augmented skeletal muscle $\mathrm{BF}$ and $\mathrm{VC}$, which likely resulted in the slowed $\mathrm{PO}_{2} m v$ fall during the crucial restcontraction transition presented herein. These results carry tremendous clinical implications particularly for those at risk for stroke, renal, and ischemic heart diseases (MacMahon et al. 1990; Lewington et al. 2002; Law et al. 2003; Lawes et al. 2003; Larsen et al. 2007, 2010; Tsuchiya et al. 2010; Carlström et al. 2011). Given the sensitivity of the RVLM to NO bioavailability (Mayorov, 2005; Gao et al. 2008), it seems logical to postulate an interaction between $\mathrm{NO}_{3}{ }^{-}, \mathrm{NO}_{2}{ }^{-}$and central cardiovascular control centers located in the brain (i.e. RVLM). Understanding these interactions will further provide a mechanistic linkage between elevated $\mathrm{NO}_{3}{ }^{-}$ingestion and the improved cardiovascular and metabolic function seen in humans (Bailey et al. 2009, 2010; Larsen et al. 2010; Kenjale et al. 2011; Vanhatalo et al. 2011; Masschelein et al.2012; Wylie et al. 2013b) and animals (Ferguson et al. 2013a,b; Hernandez et al. 2013) and thus should be the focus of future investigations. 


\section{Acknowledgements}

The authors would like to thank Ms. K. Sue Hageman, Ms. Gabrielle E. Rico, Thomas Stabler, and Dr. Tadakatsu Inagaki for excellent technical assistance. These experiments were funded by a Kansas State University SMILE award to TIM, and American Heart Association Midwest Affiliate (10GRNT4350011) and NIH (HL-108328) awards to DCP. 


\section{References}

Andrade, F.H., Reid, M.B., Allen, D.G., Westerblad, H., 1998. Effect of nitric oxide on single skeletal muscle fibres from the mouse. J. Physiol. (Lond.) 509, 577-586.

Armstrong, R.B., Hayes, D.A., Delp, M.D., 1989. Blood flow distribution in rat muscles during preexercise anticipatory response. J. Appl. Physiol. 67, 1855-1861.

Bailey, J.K., Kindig, C.A., Behnke, B.J., Musch, T.I., Schmid Schoenbein, G.W., Poole, D.C., 2000. Spinotrapezius muscle microcirculatory function: effects of surgical exteriorization. American journal of physiology.Heart and circulatory physiology 279, H3131-H3137.

Bailey, S.J., Fulford, J., Vanhatalo, A., Winyard, P.G., Blackwell, J.R., DiMenna, F.J., Wilkerson, D.P., Benjamin, N., Jones, A.M., 2010. Dietary nitrate supplementation enhances muscle contractile efficiency during knee-extensor exercise in humans. J. Appl. Physiol. 109, 135-148.

Bailey, S.J., Winyard, P., Vanhatalo, A., Blackwell, J.R., Dimenna, F.J., Wilkerson, D.P., Tarr, J., Benjamin, N., Jones, A.M., 2009. Dietary nitrate supplementation reduces the O2 cost of lowintensity exercise and enhances tolerance to high-intensity exercise in humans. J. Appl. Physiol. 107, 1144-1155.

Carlström, M., Persson, A.E., Larsson, E., Hezel, M., Scheffer, P.G., Teerlink, T., Weitzberg, E., Lundberg, J.O., 2011. Dietary nitrate attenuates oxidative stress, prevents cardiac and renal injuries, and reduces blood pressure in salt-induced hypertension. Cardiovasc. Res. 89, 574-585.

Delp, M.D., Duan, C., 1996. Composition and size of type I, IIA, IID/X, and IIB fibers and citrate synthase activity of rat muscle. J. Appl. Physiol. 80, 261-270.

Ferguson, S.K., Hirai, D.M., Copp, S.W., Holdsworth, C.T., Allen, J.D., Jones, A.M., Musch, T.I., Poole, D.C., 2013a. Effects of nitrate supplementation via beetroot juice on contracting rat skeletal muscle microvascular oxygen pressure dynamics. Respiratory Physiology Neurobiology $187,250-255$.

Ferguson, S.K., Hirai, D.M., Copp, S.W., Holdsworth, C.T., Allen, J.D., Jones, A.M., Musch, T.I., Poole, D.C., 2013b. Impact of dietary nitrate supplementation via beetroot juice on exercising muscle vascular control in rats. J. Physiol. (Lond.) 591, 547-557.

Flaim, S.F., Nellis, S.H., Toggart, E.J., Drexler, H., Kanda, K., Newman, E.D., 1984. Multiple simultaneous determinations of hemodynamics and flow distribution in conscious rat. J. Pharmacol. Methods 11, 1-39.

Gao, L., Wang, W., Liu, D., Zucker, Irving, I.H., 2007. Exercise training normalizes sympathetic outflow by central antioxidant mechanisms in rabbits with pacing-induced chronic heart failure. Circulation 115, 3095-3102. 
Gao, L., Wang,W., Zucker, I.L., 2008. Simvastatin inhibits central sympathetic outflow in heart failure by a nitric-oxide synthase mechanism. J. Pharmacol. Exp. Ther. 326, 278-285.

Gonzalez, N. C., Erwid, L. P., Painter, C.F. $3^{\text {rd }}$, Clancy, R.L., Wagner, P.D., 1994. Effect of hematocrit on systemic $\mathrm{O}_{2}$ transport in hypoxic and normoxic exercise in rats. J. Appl. Physiol. $77,1341-1348$.

Henson, L.C., Poole, D.C., Donahoe, C. P., Heber, D., 1987. Effects of exercise training on resting energy expenditure during caloric restriction. Am J Clin Nutr. 46. 893-899.

Hernández, A., Schiffer, T.A., Ivarsson, N., Cheng, A.J., Bruton, J.D., Lundberg, J.O., Weitzberg, E., Westerblad, H., 2012. Dietary nitrate increases tetanic $\left[\mathrm{Ca}^{2+}\right]$ and contractile force in mouse fast-twitch muscle. J. Physiol. (Lond.) 590, 3575-3583.

Joyner, M.J., Tschakovsky, M.E., 2003. Nitric oxide and physiologic vasodilation in human limbs: where do we go from here? Canadian journal of applied physiology 28, 475-490.

Joyner, M.J., Wilkins, B.W., 2007. Exercise hyperaemia: is anything obligatory but the hyperaemia? J. Physiol. (Lond.) 583, 855-860.

Kenjale, A.A., Ham, K.L., Stabler, T., Robbins, J.L., Johnson, J., Vanbruggen, M., Privette, G., Yim, E., Kraus, W.E., Allen, J.D., 2011. Dietary nitrate supplementation enhances exercise performance in peripheral arterial disease. J. Appl. Physiol. 110, 1582-1591.

Kishi, T., Hirooka, Y., Sakai, K., Shigematsu, H., Shimokawa, H., Takeshita, A., 2001. Overexpression of eNOS in the RVLM causes hypotension and bradycardia via GABA release. Hypertension 38, 896-901.

Lansley, K.E., Winyard, P.G., Bailey, S.J., Vanhatalo, A., Wilkerson, D.P., Blackwell, J.R., Gilchrist, M., Benjamin, N., Jones, A.M., 2011a. Acute dietary nitrate supplementation improves cycling time trial performance. Med. Sci. Sports Exerc. 43, 1125-1131.

Lansley, K.E., Winyard, P.G., Fulford, J., Vanhatalo, A., Bailey, S.J., Blackwell, J.R., Dimenna, F.J., Gilchrist, M., Benjamin, N., Jones, A.M., 2011b. Dietary nitrate supplementation reduces the $\mathrm{O} 2$ cost of walking and running: a placebo-controlled study. J. Appl. Physiol. 110, 591-600.

Larsen, F.J., Weitzberg, E., Lundberg, J.O., Ekblom, B., 2010. Dietary nitrate reduces maximal oxygen consumption while maintaining work performance in maximal exercise. Free Radic. Biol. Med. 48, 342-347.

Larsen, F.J., Weitzberg, E., Lundberg, J.O., Ekblom, B., 2007. Effects of dietary nitrate on oxygen cost during exercise. Acta physiologica 191, 59-66.

Larsen, F.J., Schiffer, T.A., Weitzberg, E., Lundberg, J.O., 2012. Regulation of mitochondrial function and energetics by reactive nitrogen oxides. Free radical biology medicine 53, 19191928. 
Law, M.R., Wald, N.J., Morris, J.K., Jordan, R.E., 2003. Value of low dose combination treatment with blood pressure lowering drugs: analysis of 354 randomized trials. BMJ.British medical journal 326, 1427-1427.

Lawes, C.M., Rodgers, A., Bennett, D.A., Parag, V., Suh, I., Ueshima, H., MacMahon, S., 2003. Blood pressure and cardiovascular disease in the Asia Pacific region. J. Hypertens. 21, 707-716.

Leek, B.T., Mudaliar, S.R., Henry, R., Mathieu Costello, O., Richardson, R.S., 2001. Effect of acute exercise on citrate synthase activity in untrained and trained human skeletal muscle. American journal of physiology.Regulatory, integrative and comparative physiology 280, R441R447.

Lewington, S., Clarke, R., Qizilbash, N., Peto, R., Collins, R., 2002. Age-specific relevance of usual blood pressure to vascular mortality: a meta-analysis of individual data for one million adults in 61 prospective studies. Lancet (London, England) 360, 1903-1913.

Lo, L.W., Vinogradov, S.A., Koch, C.J., Wilson, D.F., 1997. A new, water soluble, phosphor for oxygen measurements in vivo. Adv. Exp. Med. Biol. 428, 651-656.

Lundberg, J.O., \& Govoni, M., 2004. Inorganic nitrate is a possible source for systemic generation of nitric oxide. Free. Radic. Biol. Med. 37, 395-400.

Lundberg, J.O., Weitzberg, E., Gladwin, M. T., 2008. The nitrate-nitrite-nitric oxide pathway in physiology and therapeutics. Nat. Rev. Drug. Discov. 7, 156-167.

MacMahon, S., Peto, R., Cutler, J., Collins, R., Sorlie, P., Neaton, J., Abbott, R., Godwin, J., Dyer, A., Stamler, J., 1990. Blood pressure, stroke, and coronary heart disease. Part 1, Prolonged differences in blood pressure: prospective observational studies corrected for the regression dilution bias. Lancet (London, England) 335, 765-774.

Masschelein, E., Van Thienen, R., Wang, X., Van Schepdael, A., Thomis, M., Hespel, P., 2012. Dietary nitrate improves muscle but not cerebral oxygenation status during exercise in hypoxia. J. Appl. Physiol. 113, 736-735.

Mayorov, D.N., 2005. Selective sensitization by nitric oxide of sympathetic baroreflex in rostral ventrolateral medulla of conscious rabbits. Hypertension 45, 901-906.

Musch, T.I., Bruno, A., Bradford, G.E., Vayonis, A., Moore, R.L., 1988. Measurements of metabolic rate in rats: a comparison of techniques. J. Appl. Physiol. 65, 964-970.

Musch, T.I., Terrell, J.A., 1992. Skeletal muscle blood flow abnormalities in rats with a chronic myocardial infarction: rest and exercise. Am. J. Physiol. 262, H411-H419.

Omar, S.A., Artime, E., Webb, A.J., 2012. A comparison of organic and inorganic nitrates/nitrites. Nitric Oxide 26, 229-240. 
Poole, D.C., Behnke, B.J., McDonough, P., McAllister, R.M., Wilson, D.F., 2004. Measurement of muscle microvascular oxygen pressures: compartmentalization of phosphorescent probe. Microcirculation 11, 317-326.

Rumsey, W.L., Vanderkooi, J.M., Wilson, D.F., 1988. Imaging of phosphorescence: a novel method for measuring oxygen distribution in perfused tissue. Science 241, 1649-1651.

Tsuchiya, K., Tomita, S., Ishizawa, K., Abe, S., Ikeda, Y., Kihira, Y., Tamaki, T., 2010. Dietary nitrite ameliorates renal injury in L-NAME-induced hypertensive rats. Nitric Oxide 22, 98-103.

Vanhatalo, A., Bailey, S.J., Blackwell, J.R., DiMenna, F.J., Pavey, T., Wilkerson, D.P., Benjamin, N., Winyard, P.G., Jones, A.M, 2010. Acute and chronic effects of dietary nitrate supplementation on blood pressure and the physiological responses to moderate-intensity and incremental exercise. American Journal of Physiology: Regulatory, Integrative and Comparative Physiology 299, R1121-R1131.

Vanhatalo, A., Fulford, J., Bailey, S.J., Blackwell, J.R., Winyard, P.J., Jones, A.M., 2011. Dietary nitrate reduces muscle metabolic perturbation and improves exercise tolerance in hypoxia. J. Physiol. (Lond.) 589, 5517-5528.

Wylie, L.J., Kelly, J., Bailey, S.J., Blackwell, J.R., Skiba, P.F., Winyard, P.G., Jeukendrup, A.E., Vanhatalo, A., Jones, A.M., 2013a. Beetroot juice and exercise: pharmacodynamic and doseresponse relationships. J. Appl. Physiol. 115, 325-336.

Wylie, L.J., Mohr, M., Krustrup, P., Jackman, S.R., Ermidis, G., Kelly, J., Black, M.I., Bailey, S.J., Vanhatalo, A., Jones A.M., 2013b. Dietary nitrate supplementation improves team sportspecific intense intermittent exercise performance. Eur. J. Appl. Physiol. 113, 1673-1684. 
Table 1. Effects of low dose and high dose BR supplementation on resting hindlimb muscle BF $(\mathrm{ml} / \mathrm{min} / 100 \mathrm{~g})$ and $\mathrm{VC}(\mathrm{ml} / \mathrm{min} / 100 \mathrm{~g} / \mathrm{mmHg})$.

\begin{tabular}{|c|c|c|c|c|c|c|}
\hline & \multicolumn{3}{|c|}{$\mathbf{B F}$} & \multicolumn{3}{|c|}{ VC } \\
\hline & Control & BRLD & BRHD & Control & BRLD & BRHD \\
\hline \multicolumn{7}{|l|}{ Ankle extensors } \\
\hline Soleus $(9 \%)$ & $87 \pm 16$ & $119 \pm 17$ & $107 \pm 33$ & $0.62 \pm 0.11$ & $0.96 \pm 0.12$ & $0.79 \pm 0.24$ \\
\hline Plantaris $(80 \%)$ & $15 \pm 2$ & $16 \pm 2$ & $9 \pm 2$ & $0.11 \pm 0.01$ & $0.13 \pm 0.01$ & $0.07 \pm 0.02$ \\
\hline Gastrocnemius, red (14\%) & $43 \pm 7$ & $56 \pm 9$ & $58 \pm 19$ & $3.07 \pm 0.05$ & $0.44 \pm 0.07$ & $0.43 \pm 0.13$ \\
\hline Gastrocnemius, white $(100 \%)$ & $14 \pm 2$ & $12 \pm 2$ & $10 \pm 3$ & $0.10 \pm 0.05$ & $0.10 \pm 0.02$ & $0.08 \pm 0.02$ \\
\hline Gastrocnemius, mixed (91\%) & $14 \pm 2$ & $16 \pm 2$ & $16 \pm 4$ & $0.10 \pm 0.02$ & $0.12 \pm 0.02$ & $0.12 \pm 0.02$ \\
\hline Tibialis posterior $(\mathbf{7 3 \%})$ & $17 \pm 2$ & $18 \pm 3$ & $16 \pm 5$ & $0.12 \pm 0.01$ & $0.14 \pm 0.02$ & $0.12 \pm 0.03$ \\
\hline Flexor digitorum longus $(68 \%)$ & $19 \pm 2$ & $24 \pm 2$ & $10 \pm 2$ & $0.15 \pm 0.02$ & $0.19 \pm 0.02$ & $0.08 \pm 0.01$ \\
\hline Flexor halicus longus $(71 \%)$ & $13 \pm 2$ & $12 \pm 2$ & $9 \pm 2$ & $0.09 \pm 0.01$ & $0.09 \pm 0.01$ & $0.07 \pm 0.01$ \\
\hline \multicolumn{7}{|l|}{ Ankle flexors } \\
\hline Tibialis anterior, red $(63 \%)$ & $19 \pm 3$ & $27 \pm 7$ & $21 \pm 10$ & $0.14 \pm 0.02$ & $0.21 \pm 0.06$ & $0.15 \pm 0.07$ \\
\hline Tibialis anterior, white $(80 \%)$ & $20 \pm 2$ & $18 \pm 3$ & $16 \pm 4$ & $0.14 \pm 0.02$ & $0.15 \pm 0.02$ & $0.12 \pm 0.03$ \\
\hline Extensor digitorum longus ( $76 \%)$ & $16 \pm 2$ & $15 \pm 2$ & $15 \pm 4$ & $0.12 \pm 0.01$ & $0.12 \pm 0.01$ & $0.11 \pm 0.03$ \\
\hline Peroneals (67\%) & $17 \pm 3$ & $15 \pm 2$ & $19 \pm 4$ & $0.12 \pm 0.02$ & $0.12 \pm 0.02$ & $0.14 \pm 0.03$ \\
\hline \multicolumn{7}{|l|}{ Knee extensors } \\
\hline Vastus intermedius (4\%) & $46 \pm 9$ & $84 \pm 18$ & $93 \pm 48$ & $0.32 \pm 0.06$ & $0.66 \pm 0.13$ & $0.69 \pm 0.35$ \\
\hline Vastus medialis (82\%) & $15 \pm 2$ & $17 \pm 3$ & $25 \pm 9$ & $0.10 \pm 0.01$ & $0.13 \pm 0.02$ & $0.19 \pm 0.06$ \\
\hline Vastus lateralis, red (35\%) & $40 \pm 6$ & $66 \pm 16$ & $83 \pm 31$ & $0.28 \pm 0.04$ & $0.19 \pm 0.04$ & $0.61 \pm 0.22$ \\
\hline Vastus lateralis, white $(100 \%)$ & $16 \pm 2$ & $14 \pm 2$ & $13 \pm 3$ & $0.11 \pm 0.01$ & $0.11 \pm 0.02$ & $0.10 \pm 0.02$ \\
\hline Vastus lateralis, mixed (89\%) & $16 \pm 1$ & $21 \pm 4$ & $29 \pm 9$ & $0.12 \pm 0.01$ & $0.17 \pm 0.04$ & $0.21 \pm 0.06$ \\
\hline Rectus femoris, red $(66 \%)$ & $23 \pm 4$ & $24 \pm 4$ & $29 \pm 14$ & $0.16 \pm 0.03$ & $0.19 \pm 0.04$ & $0.20 \pm 0.10$ \\
\hline Rectus femoris, white $(100 \%)$ & $15 \pm 2$ & $16 \pm 3$ & $17 \pm 5$ & $0.11 \pm 0.01$ & $0.13 \pm 0.02$ & $0.12 \pm 0.03$ \\
\hline \multicolumn{7}{|l|}{$\underline{\text { Knee flexors }}$} \\
\hline Biceps femoris anterior $(100 \%)$ & $11 \pm 1$ & $9 \pm 1$ & $10 \pm 2$ & $0.07 \pm 0.01$ & $0.07 \pm 0.01$ & $0.08 \pm 0.01$ \\
\hline Biceps femoris posterior $(92 \%)$ & $11 \pm 2$ & $12 \pm 2$ & $15 \pm 3$ & $0.08 \pm 0.01$ & $0.10 \pm 0.01$ & $0.11 \pm 0.02$ \\
\hline Semitendinosus (83\%) & $12 \pm 2$ & $14 \pm 2$ & $18 \pm 5$ & $0.08 \pm 0.01$ & $0.11 \pm 0.02$ & $0.14 \pm 0.03$ \\
\hline Semimembranosus, red $(72 \%)$ & $15 \pm 2$ & $19 \pm 3$ & $28 \pm 9$ & $0.11 \pm 0.02$ & $0.15 \pm 0.02$ & $0.21 \pm 0.06$ \\
\hline Semimembranosus, white $(100 \%)$ & $13 \pm 2$ & $11 \pm 1$ & $12 \pm 2$ & $0.09 \pm 0.01$ & $0.09 \pm 0.01$ & $0.09 \pm 0.01$ \\
\hline \multicolumn{7}{|l|}{ Thigh adductors } \\
\hline Adductor longus (5\%) & $115 \pm 7$ & $142 \pm 12$ & $148 \pm 12$ & $0.84 \pm 0.06$ & $1.12 \pm 0.10$ & $1.19 \pm 0.12$ \\
\hline Adductor magnus \& brevis $(89 \%)$ & $15 \pm 3$ & $16 \pm 3$ & $23 \pm 7$ & $0.11 \pm 0.02$ & $0.13 \pm 0.02$ & $0.17 \pm 0.05$ \\
\hline Gracilis (77\%) & $16 \pm 3$ & $17 \pm 2$ & $20 \pm 4$ & $0.11 \pm 0.02$ & $0.13 \pm 0.01$ & $0.15 \pm 0.03$ \\
\hline Pectineus (69\%) & $17 \pm 2$ & $23 \pm 4$ & $28 \pm 7$ & $0.12 \pm 0.01$ & $0.19 \pm 0.03$ & $0.21 \pm 0.04$ \\
\hline
\end{tabular}

Data are mean \pm SEM. Values in parentheses indicate \% type IIb $+\mathrm{d} / \mathrm{x}$ according to Delp \& Duan (1996).

Control; $n=10$, BRLD; $n=14$, BRHD; $n=6$. 
Table 2. Effects of low dose and high dose BR supplementation on exercising hindlimb muscle BF $(\mathrm{ml} / \mathrm{min} / 100 \mathrm{~g})$ and $\mathrm{VC}(\mathrm{ml} / \mathrm{min} / 100 \mathrm{~g} / \mathrm{mmHg})$.

\begin{tabular}{|c|c|c|c|c|c|c|}
\hline & \multicolumn{3}{|c|}{ BF } & \multicolumn{3}{|c|}{$\mathbf{V C}$} \\
\hline & Control & BRLD & BRHD & Control & BRLD & BRHD \\
\hline \multicolumn{7}{|l|}{ Ankle extensors } \\
\hline Soleus (9\%) & $297 \pm 46$ & $251 \pm 19$ & $328 \pm 39$ & $2.15 \pm 0.33$ & $2.04 \pm 0.20$ & $2.60 \pm 0.26$ \\
\hline Plantaris $(80 \%)$ & $208 \pm 17$ & $194 \pm 18$ & $249 \pm 10 \dagger$ & $1.51 \pm 0.11$ & $1.56 \pm 0.17$ & $2.00 \pm 0.06^{*}+$ \\
\hline Gastrocnemius, red (14\%) & $444 \pm 48$ & $391 \pm 40$ & $507 \pm 42$ & $3.21 \pm 0.32$ & $3.13 \pm 0.28$ & $4.07 \pm 0.31 * \dagger$ \\
\hline Gastrocnemius, white (100\%) & $44 \pm 7$ & $42 \pm 8$ & $71 \pm 14 * \dagger$ & $0.31 \pm 0.05$ & $0.32 \pm 0.05$ & $0.56 \pm 0.10^{*}+$ \\
\hline Gastrocnemius, mixed (91\%) & $153 \pm 13$ & $135 \pm 12$ & $214 \pm 19 *+$ & $1.11 \pm 0.08$ & $1.08 \pm 0.10$ & $1.71 \pm 0.11^{*}+$ \\
\hline Tibialis posterior $(\mathbf{7 3 \%})$ & $121 \pm 18$ & $111 \pm 11$ & $137 \pm 22$ & $0.88 \pm 0.13$ & $0.89 \pm 0.09$ & $1.10 \pm 0.18$ \\
\hline Flexor digitorum longus (68\%) & $103 \pm 15$ & $113 \pm 19$ & $106 \pm 19$ & $0.74 \pm 0.10$ & $0.92 \pm 0.17$ & $0.84 \pm 0.15$ \\
\hline Flexor halicus longus $(\mathbf{7 1 \% )}$ & $74 \pm 11$ & $69 \pm 11$ & $88 \pm 11$ & $0.53 \pm 0.07$ & $0.55 \pm 0.08$ & $0.70 \pm 0.07$ \\
\hline \multicolumn{7}{|l|}{$\underline{\text { Ankle flexors }}$} \\
\hline Tibialis anterior, red $(63 \%)$ & $347 \pm 38$ & $303 \pm 22$ & $388 \pm 35 \dagger$ & $2.50 \pm 0.26$ & $2.38 \pm 0.16$ & $3.08 \pm 0.19 \dagger$ \\
\hline Tibialis anterior, white (80\%) & $120 \pm 15$ & $109 \pm 11$ & $170 \pm 24 *+$ & $0.86 \pm 0.10$ & $0.86 \pm 0.08$ & $1.34 \pm 0.16^{*}+$ \\
\hline Extensor digitorum longus (76\%) & $57 \pm 8$ & $60 \pm 6$ & $83 \pm 13^{*}+$ & $0.46 \pm 0.05$ & $0.47 \pm 0.04$ & $0.66 \pm 0.09 * \dagger$ \\
\hline Peroneals (67\%) & $129 \pm 13$ & $123 \pm 10$ & $172 \pm 8^{*}+$ & $0.93 \pm 0.09$ & $0.98 \pm 0.08$ & $1.38 \pm 0.05^{*}+$ \\
\hline \multicolumn{7}{|l|}{$\underline{\text { Knee extensors }}$} \\
\hline Vastus intermedius (4\%) & $371 \pm 41$ & $320 \pm 28$ & $358 \pm 54$ & $2.68 \pm 0.29$ & $2.54 \pm 0.23$ & $2.88 \pm 0.41$ \\
\hline Vastus medialis $(\mathbf{8 2 \%})$ & $122 \pm 18$ & $111 \pm 13$ & $185 \pm 36$ & $0.88 \pm 0.12$ & $0.87 \pm 0.10$ & $1.48 \pm 0.28 * \dagger$ \\
\hline Vastus lateralis, red (35\%) & $393 \pm 47$ & $327 \pm 29$ & $486 \pm 48 \dagger$ & $2.84 \pm 0.32$ & $2.60 \pm 0.23$ & $3.91 \pm 0.39 *+$ \\
\hline Vastus lateralis, white $(100 \%)$ & $32 \pm 5$ & $33 \pm 5$ & $51 \pm 10^{*} \dagger$ & $0.23 \pm 0.03$ & $0.26 \pm 0.04$ & $0.40 \pm 0.07^{*}+$ \\
\hline Vastus lateralis, mixed (89\%) & $169 \pm 23$ & $151 \pm 14$ & $243 \pm 17 *+$ & $1.23 \pm 0.16$ & $1.20 \pm 0.11$ & $1.95 \pm 0.13^{*}+$ \\
\hline Rectus femoris, red (66\%) & $233 \pm 35$ & $245 \pm 15$ & $33 \pm 37 *+$ & $1.69 \pm 0.24$ & $1.95 \pm 0.13$ & $2.64 \pm 0.30^{*}+$ \\
\hline Rectus femoris, white (100\%) & $103 \pm 14$ & $94 \pm 8$ & $197 \pm 38^{*}+$ & $0.74 \pm 0.09$ & $0.75 \pm 0.06$ & $1.55 \pm 0.27^{*}+$ \\
\hline \multicolumn{7}{|l|}{$\underline{\text { Knee flexors }}$} \\
\hline Biceps femoris anterior $(100 \%)$ & $49 \pm 9$ & $50 \pm 7$ & $77 \pm 16^{*} \dagger$ & $0.36 \pm 0.06$ & $0.40 \pm 0.05$ & $0.63 \pm 0.13^{*} \dagger$ \\
\hline Biceps femoris posterior $(92 \%)$ & $79 \pm 9$ & $81 \pm 9$ & $135 \pm 13$ & $0.57 \pm 0.07$ & $0.65 \pm 0.07$ & $1.09 \pm 0.10^{*} \dagger$ \\
\hline Semitendinosus $(\mathbf{8 3} \%)$ & $57 \pm 7$ & $51 \pm 5$ & $80 \pm 13^{*}+$ & $0.41 \pm 0.05$ & $0.40 \pm 0.04$ & $0.63 \pm 0.11^{*}+$ \\
\hline Semimembranosus, red (72\%) & $120 \pm 16$ & $116 \pm 10$ & $172 \pm 17^{*}+$ & $0.87 \pm 0.11$ & $0.93 \pm 0.10$ & $1.38 \pm 0.13^{*} \dagger$ \\
\hline Semimembranosus, white (100\%) & $34 \pm 6$ & $32 \pm 4$ & $67 \pm 14^{*}+$ & $0.25 \pm 0.04$ & $0.25 \pm 0.03$ & $0.54 \pm 0.11 * \dagger$ \\
\hline \multicolumn{7}{|l|}{ Thigh adductors } \\
\hline Adductor longus (5\%) & $321 \pm 42$ & $268 \pm 20$ & $333 \pm 51$ & $2.32 \pm 0.29$ & $2.17 \pm 0.20$ & $2.66 \pm 0.40$ \\
\hline Adductor magnus \& brevis (89\%) & $82 \pm 9$ & $71 \pm 7$ & $116 \pm 19 * \dagger$ & $0.59 \pm 0.06$ & $0.60 \pm 0.06$ & $0.93 \pm 0.14^{*} \dagger$ \\
\hline Gracilis (77\%) & $42 \pm 5$ & $41 \pm 6$ & $60 \pm 11$ & $0.30 \pm 0.03$ & $0.33 \pm 0.06$ & $0.48 \pm 0.08^{*}$ \\
\hline Pectineus $(69 \%)$ & $49 \pm 7$ & $59 \pm 8$ & $84 \pm 17^{*}$ & $0.35 \pm 0.05$ & $0.46 \pm 0.06$ & $0.68 \pm 0.14^{*} \dagger$ \\
\hline
\end{tabular}

Data are mean \pm SEM. Values in parentheses indicate \% type IIb $+\mathrm{d} / \mathrm{x}$ according to Delp \& Duan (1996).

Control; $n=10$, BRLD; $n=14$ BRHD; $n=6 .{ }^{*} P<0.05$ vs. control. $+P<0.05$ vs. BRLD. 
Table 3. Effects of low dose and high dose BR supplementation on kidney and splanchnic region organ $\mathrm{BF}(\mathrm{ml} / \mathrm{min} / 100 \mathrm{~g})$ and $\mathrm{VC}(\mathrm{ml} / \mathrm{min} / 100 \mathrm{~g} / \mathrm{mmHg})$ at rest and during exercise.

\begin{tabular}{|c|c|c|c|c|c|c|}
\hline & \multicolumn{3}{|c|}{ Rest } & \multicolumn{3}{|c|}{ Exercise } \\
\hline & Control & BRLD & BRHD & Control & BRLD & BRHD \\
\hline \multicolumn{7}{|l|}{$\underline{\mathbf{B F}}$} \\
\hline Kidney & $414 \pm 29$ & $447 \pm 32$ & $521 \pm 32 *$ & $421 \pm 47$ & $372 \pm 35$ & $436 \pm 52 \dagger$ \\
\hline Stomach & $82 \pm 8$ & $94 \pm 13$ & $71 \pm 16$ & $68 \pm 15$ & $51 \pm 6 \dagger$ & $49 \pm 9$ \\
\hline Adrenals & $557 \pm 91$ & $601 \pm 57$ & $667 \pm 67$ & $349 \pm 79$ & $321 \pm 49$ & $594 \pm 188$ \\
\hline Spleen & $345 \pm 54$ & $332 \pm 37$ & $501 \pm 134$ & $63 \pm 16 \dagger$ & $81 \pm 14 \dagger$ & $99 \pm 33 \dagger$ \\
\hline Pancreas & $117 \pm 11$ & $112 \pm 14$ & $86 \pm 15$ & $115 \pm 15$ & $103 \pm 10$ & $116 \pm 28$ \\
\hline Sm. Intestine & $304 \pm 17$ & $361 \pm 38$ & $269 \pm 38$ & $247 \pm 30$ & $238 \pm 21 \dagger$ & $255 \pm 53$ \\
\hline Lg. Intestine & $131 \pm 13$ & $153 \pm 18$ & $139 \pm 18$ & $135 \pm 15$ & $126 \pm 13$ & $142 \pm 21$ \\
\hline Liver** & $37 \pm 13$ & $32 \pm 6$ & $40 \pm 8$ & $17 \pm 4$ & $18 \pm 2$ & $41 \pm 11$ \\
\hline \multicolumn{7}{|l|}{$\underline{\mathrm{VC}}$} \\
\hline Kidney & $3.04 \pm 0.27$ & $3.65 \pm 0.32$ & $4.15 \pm 0.27^{*}$ & $3.04 \pm 0.31$ & $3.13 \pm 0.43$ & $3.51 \pm 0.44$ \\
\hline Stomach & $0.59 \pm 0.06$ & $0.75 \pm 0.10$ & $0.54 \pm 0.09$ & $0.50 \pm 0.11$ & $0.41 \pm 0.05 \dagger$ & $0.39 \pm 0.07$ \\
\hline Adrenals & $4.06 \pm 0.72$ & $4.71 \pm 0.37$ & $5.42 \pm 0.80$ & $2.86 \pm 0.49$ & $2.51 \pm 0.37 \dagger$ & $4.79 \pm 1.57$ \\
\hline Spleen & $2.50 \pm 0.40$ & $2.63 \pm 0.27$ & $3.71 \pm 0.85$ & $0.45 \pm 0.11 \dagger$ & $0.64 \pm 0.28 \dagger$ & $0.79 \pm 0.28$ \\
\hline Pancreas & $0.85 \pm 0.08$ & $0.88 \pm 0.11$ & $0.65 \pm 0.09$ & $0.83 \pm 0.11$ & $0.83 \pm 0.08$ & $0.92 \pm 0.23 \dagger$ \\
\hline Sm. Intestine & $2.18 \pm 0.14$ & $2.87 \pm 0.28$ & $2.06 \pm 0.25$ & $1.72 \pm 0.20$ & $1.89 \pm 0.17 \dagger$ & $2.00 \pm 0.43$ \\
\hline Lg. Intestine & $0.95 \pm 0.10$ & $1.21 \pm 0.14$ & $1.09 \pm 0.11$ & $0.98 \pm 0.10$ & $1.00 \pm 0.10$ & $1.13 \pm 0.16$ \\
\hline Liver** & $0.26 \pm 0.12$ & $0.21 \pm 0.04$ & $0.26 \pm 0.05$ & $0.12 \pm 0.03$ & $0.15 \pm 0.02$ & $0.32 \pm 0.08$ \\
\hline
\end{tabular}

Data are mean \pm SEM. ${ }^{*}, P<0.05$ vs. Control. $\dagger, P<0.05$ vs. rest. $* *$ Indicates arterial, not portal, $\mathrm{BF}$ and VC. 
Table 4. Microvascular partial pressure of $\mathrm{O}_{2}\left(\mathrm{PO}_{2} \mathrm{mv}\right)$ kinetics parameters at rest and during contractions for control, BRLD and BRHD rats.

\begin{tabular}{lccc}
\hline & Control & BRLD & BRHD \\
\hline $\mathbf{P O}_{\mathbf{2}} \boldsymbol{m v} \boldsymbol{v}_{(\mathbf{B L})}(\mathbf{m m H g})$ & $31.1 \pm 2.0$ & $30.1 \pm 1.9$ & $26.4 \pm 2.8$ \\
$\Delta_{\mathbf{1}} \mathbf{P O}_{\mathbf{2}} \mathbf{m v}(\mathbf{m m H g})$ & $16.7 \pm 1.5$ & $12.9 \pm 0.7^{*}$ & $11.8 \pm 0.9^{*}$ \\
$\Delta_{\mathbf{2}} \mathbf{P O}_{\mathbf{2}} \mathbf{m v}(\mathbf{m m H g})$ & $3.9 \pm 0.8$ & $3.6 \pm .3$ & $3.8 \pm 0.4$ \\
$\Delta_{\text {total }} \mathbf{P O} \mathbf{O}_{\mathbf{2}} \mathbf{m v}(\mathbf{m m H g})$ & $13.6 \pm 1.6$ & $11.1 \pm 1$ & $9.6 \pm 1.5$ \\
$\mathbf{P O}_{\mathbf{2}} \mathbf{m v}$ (steady-state) $(\mathbf{m m H g})$ & $18 \pm 1.7$ & $19 \pm 1.4$ & $17.7 \pm 2.0$ \\
$\mathbf{T D}_{\mathbf{1}}(\mathbf{s})$ & $6.7 \pm 1.5$ & $8.6 \pm 0.9$ & $12.9 \pm 2.8^{*}$ \\
$\mathbf{T D}_{\mathbf{2}}(\mathbf{s})$ & $49.8 \pm 11.2$ & $54 \pm 15.6$ & $27 \pm 5.5$ \\
$\boldsymbol{\tau}_{\mathbf{1}}(\mathbf{s})$ & $9.9 \pm 1.2$ & $8.6 \pm 0.9$ & $10.4 \pm 2.2$ \\
$\boldsymbol{\tau}_{\mathbf{2}}(\mathbf{s})$ & $89.4 \pm 18.7$ & $93.9 \pm 21.2$ & $86.1 \pm 10.9$ \\
$\mathbf{M R T}$ & $16.6 \pm 2.1$ & $20.9 \pm 1.9$ & $23.3 \pm 4.7^{*}$ \\
$\Delta_{\mathbf{1}} \mathbf{P O}_{\mathbf{2}} \mathbf{m v} / \boldsymbol{\tau}_{\mathbf{1}}(\mathbf{m m H g} / \mathbf{s})$ & $1.9 \pm 0.3$ & $1.3 \pm 0.2$ & $1.4 \pm 0.3$ \\
\hline
\end{tabular}

Values are mean \pm SEM. Where second component model averages are shown the value reflects only those rats where a two-component model was applied to describe the $\mathrm{PO}_{2} m v$ data (control: $\mathrm{n}=9$, BRLD: $\mathrm{n}=6$, BRHD: $\mathrm{n}=3$ ). $\mathrm{P} m \mathrm{O}_{2(\mathrm{BL})}$, pre-contraction $\mathrm{PO}_{2} m v ; \Delta_{1} \mathrm{PO}_{2} m v$, amplitude of the first component; $\Delta_{2} \mathrm{PO}_{2} m v$, amplitude of the second component; $\Delta_{\text {total }} \mathrm{PO}_{2} m v$, overall amplitude regardless of one- or two-component model fit; $\mathrm{PO}_{2} m v$ (steady-state), $\mathrm{PO}_{2} m v$ during contracting steady-state; $\mathrm{TD}_{1}$, time delay for the first component; $\mathrm{TD}_{2}$, time delay for the second component; $\tau_{1}$, time constant for the first component; $\tau_{2}$, time constant for the second component; $\mathrm{MRT}_{1}$, mean response time describing the overall kinetics response; $\Delta_{1} \mathrm{PO}_{2} m v / \tau_{1}$, parameter describing the relative rate of $\mathrm{PO}_{2} m v$ fall.

$* P<0.05$ vs. control. 


\section{Figure captions}

Figure 1. Top panel: Post-supplementation plasma $\left[\mathrm{NO}_{3}{ }^{-}\right]$for control, BRLD and BRHD rats.

Bottom panel: Post-supplementation plasma $\left[\mathrm{NO}_{2}{ }^{-}\right]$for control, BRLD and BR rats. ${ }^{*} \mathrm{P}<0.05$ versus control $\# P<0.05$ versus BRLD.

Figure 2. Resting and exercising mean arterial pressures for control, BRLD and BRHD rats. ${ }^{*} P<0.05$ versus control.

Figure 3. Total hindlimb BF and VC for control, BRLD and BRHD rats during submaximal locomotory exercise. ${ }^{*} \mathrm{P}<0.05$ versus control.

Figure 4. Raw representative $\mathrm{PO}_{2} m v$ profiles for control, BRLD and BRHD rats during $180 \mathrm{~s}$ of 1-Hz twitch contractions. 
Figure 1.
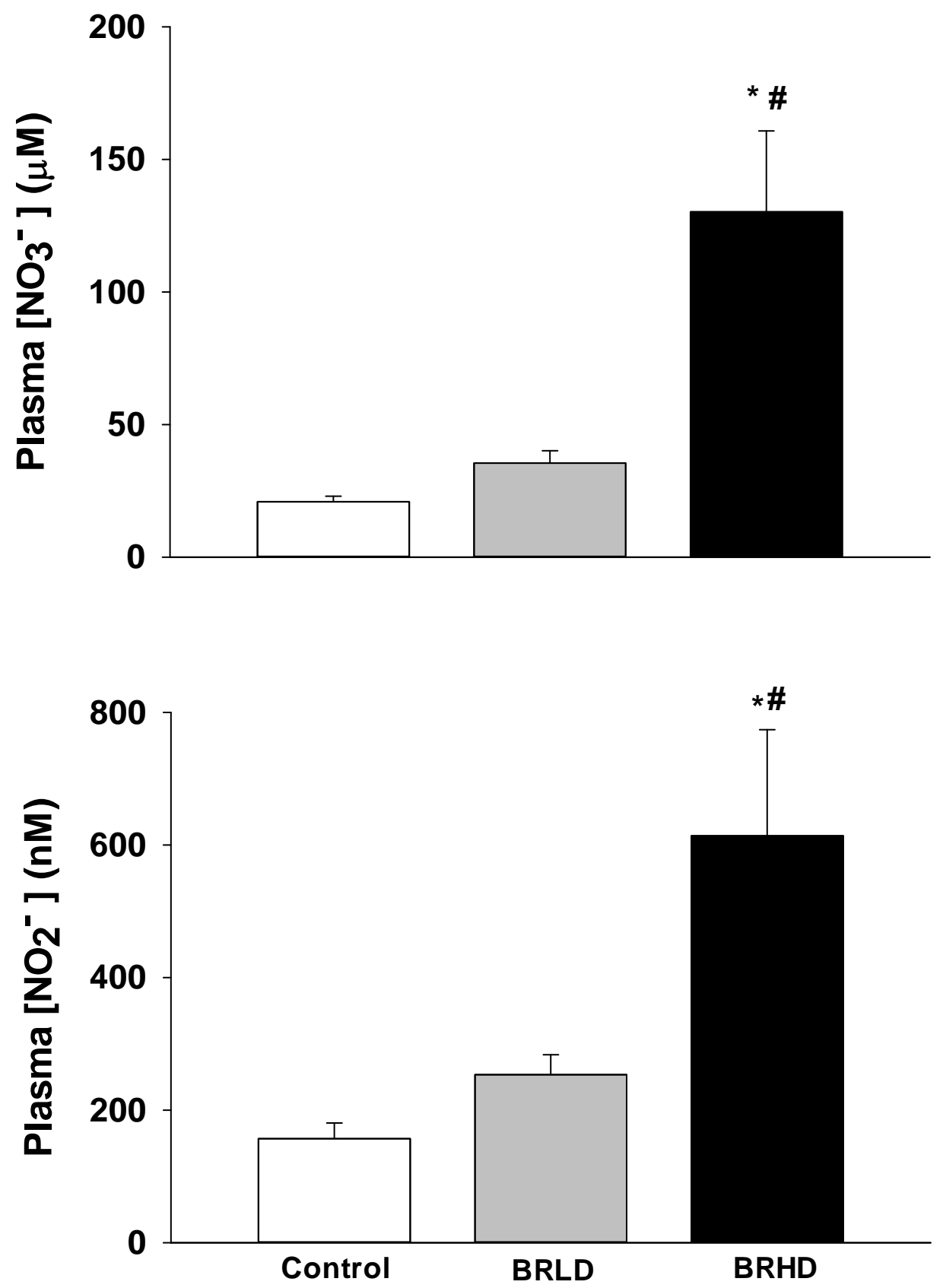
Figure 2.

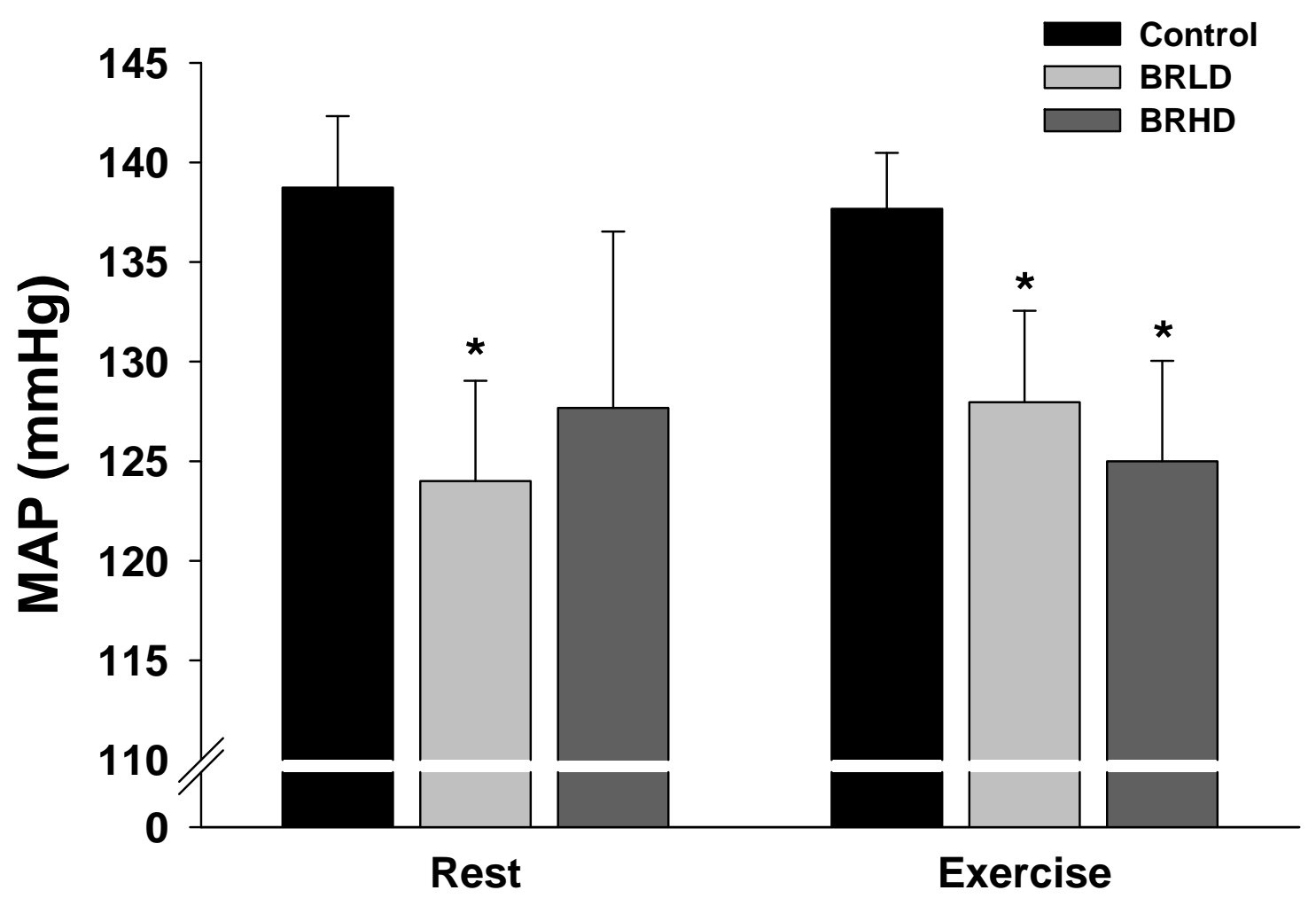


Figure 3.
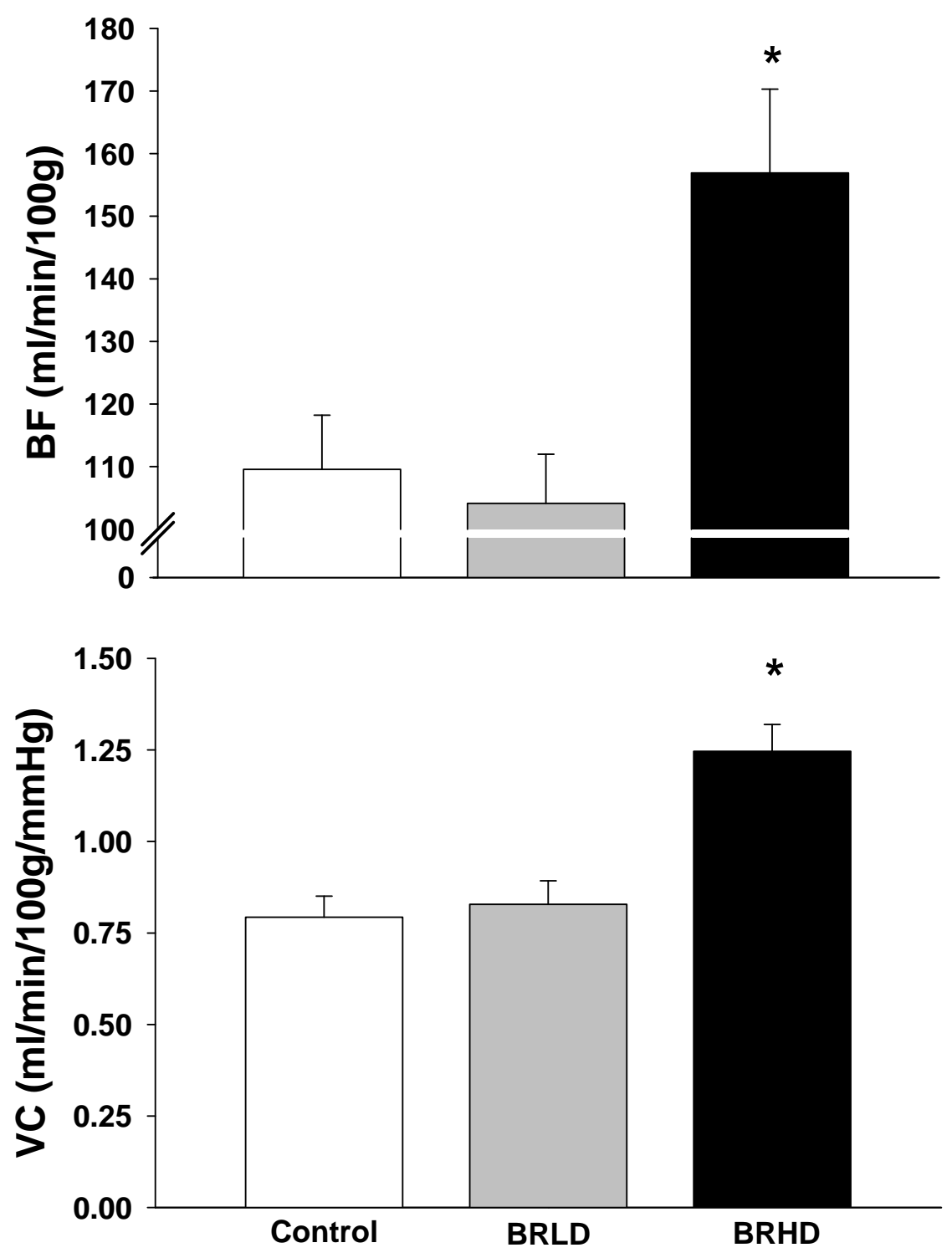
Figure 4.

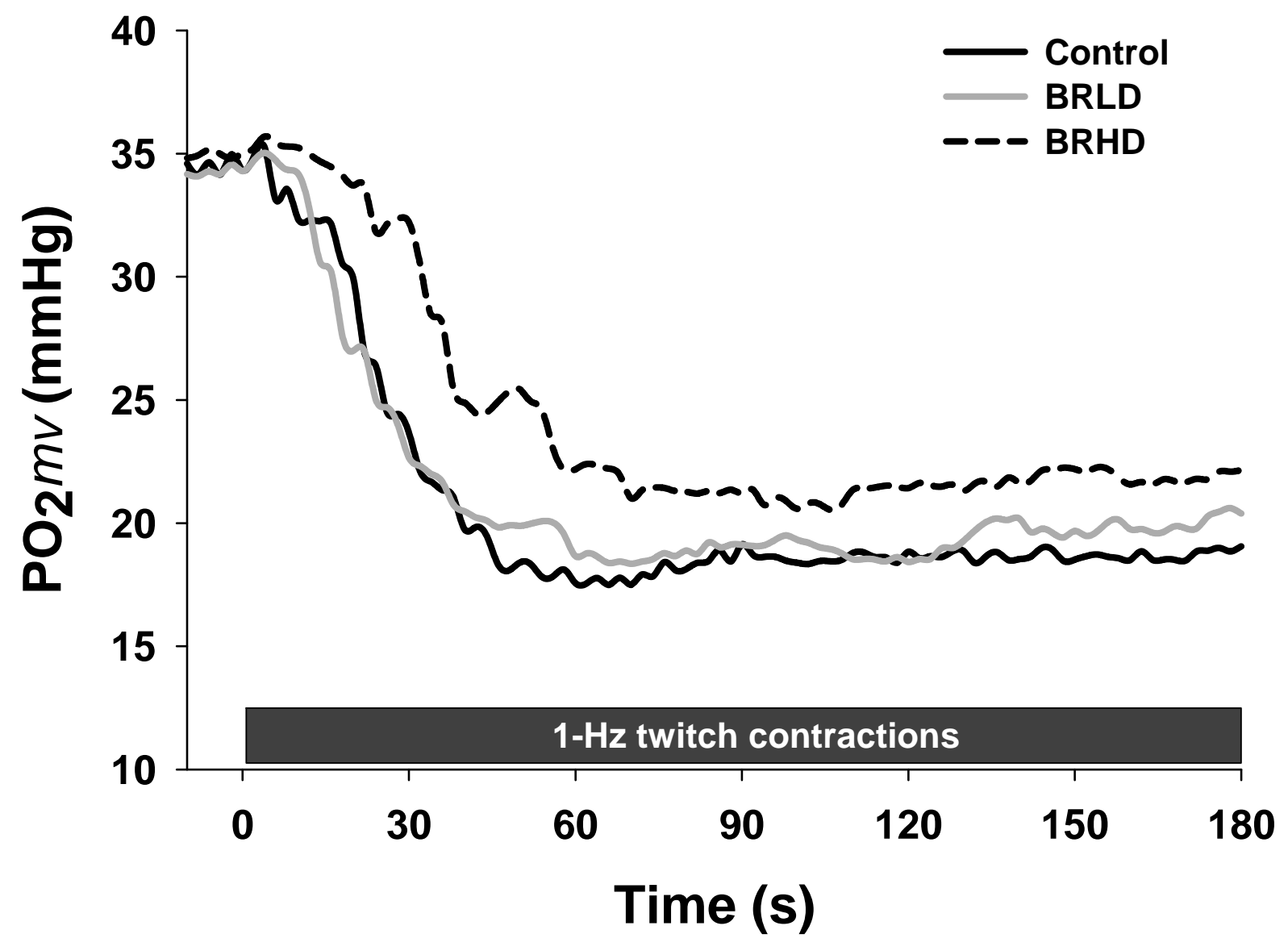

